\title{
Glycogen storage disease: report of two cases in the city of Cartagena
}

\author{
Ciro C. Alvear, MSc ${ }^{1}, M$ iriam Barboza, MD²,Zeudy K. Rodríguez, MD 3
}

\section{SUMMARY}

Objective: to report two cases of children with type Ia glycogen storage disease compatible with Von Gierke disease, suspected in the presence of findings such as hepatomegaly, nephromegaly, hypoglycemia, and stunted growth.

Method: Presentation of the clinical records of two patients referred to the diagnostic unit of innate errors of metabolism of the Faculty of Medicine in Universidad de Cartagena.

Results: The first case reported was a child who debuted with acute cyanosis without widespread neurological deficit when he was eleven months old, followed by hepatomegaly at two years of age. At 4 years of age, symptoms reappeared with similar characteristics: hypoglycemia, growth failure, and persistent hepatomegaly detected on physical examination. With the precedent that an older brother that presented similar symptoms was suspected of glycogen storage disease, a biopsy was performed and confirmed liver glycogen storage with normal structure. The patient's treatment was modification of dietary habits (small, frequent feedings during the day) and cornstarch. The second event was the older brother who consulted for the first time when he was 18 months old due to prolonged diarrhea. Hepatomegaly was documented by ultrasound study without kidney compromise and no hypoglycemia was found.

Recommendations: It is necessary for the entire health team to be trained to detect rare diseases such as glycogen storage disease. If they make early diagnoses and establish support groups for interdisciplinary management of such diseases, they may change the prognosis and quality of life of these children.

Keywords: Hepatomegaly; Nephromegaly; Hypoglycemia; Stunted growth; Metabolic screening; Glucose-6-Phosphatase; Diet.

\section{Enfermedades de depósito de glucógeno: informe de dos casos en la ciudad de Cartagena}

\section{RESUMEN}

Objetivo: Comunicar dos casos de niños con glucogenosis compatibles con el tipo Ia o enfermedad de Von Gierke, que se debe sospechar ante la presencia de hallazgos como hepatomegalia, nefromegalia, hipoglicemia y talla baja.

Método: Presentación de las historias clínicas de dos pacientes remitidos a la unidad de diagnóstico de errores innatos del metabolismo de la Facultad de Medicina de la Universidad de Cartagena.

Resultados: El primer caso es un niño que a los once meses de edad hizo crisis de cianosis generalizada sin déficit neurológico, y a los dos años tuvo hepatomegalia. A los cuatro años vuelve a presentar el mismo cuadro con iguales características más hipoglicemia y al examen físico talla baja y persistencia de la hepatomegalia. Con el antecedente de un hermano mayor que mostró sintomatología similar se sospechó glucogenosis; se tomó una biopsia de hígado y se confirmó depósito de glucógeno hepático de estructura normal. Se manejó con dieta fraccionada y fécula de maíz. El segundo caso se trata del hermano mayor quien consultó por primera vez a los 18 meses de edad con diarrea prolongada. Se documentó hepatomegalia por estudio ecográfico sin compromiso renal y nunca cursó con hipoglicemia.

Recomendaciones: Es necesario que todo el equipo de salud esté capacitado para descubrir enfermedades raras como la glucogenosis. Esto puede cambiar el pronóstico y calidad de vida de los niños si se hace un diagnóstico precoz y se establecen grupos de apoyo interdisciplinarios en el manejo de este grupo de enfermedades.

1. Clinical Biochemistry, Professor Faculty of Medicine, Universidad de Cartagena, Cartagena, Colombia. e-mail: cicealse@yahoo.es

2. Professor, Faculty of Medicine, Universidad de Cartagena, Cartagena, Colombia. e-mail: mirbar2001@ yahoo.com

3. Resident Physician in Pediatrics, Universidad de Cartagena, Cartagena, Colombia. e-mail: zeudy.rodriguez@gmail.com Received for publication December 1, 2008 Accepted for publication January 12th, 2010 
Palabras clave: Hepatomegalia; Nefromegalia; Hipoglicemia; Talla baja; Retardo en el crecimiento; Tamizaje metabólico; Glucosa 6 fosfatasa; Dieta.

Glycogen storage disease (GSD) or glycogenosis include hereditary diseases caused by abnormalities of the enzymes that regulate the synthesis and degradation of glycogen. Glycogen synthesisis produced in numerous tissues, especially in the liver, kidneys, and muscle; and mainly deposited in the liver and muscle, but the latter lacks glucose-6-phosphatase, an enzyme that acts in the light of the endoplasmic reticulum and turns glucose-6phosphatase into free glucose $\mathrm{e}^{2,3}$ and, hence, insufficient amounts of glucose is liberated onto the systemic circulation given that the function of muscular glycogen is to serve as a source of energy for its own activity.

The clinical manifestations of diseases with glycogen storage are often due to hypoglycemia with or without increased glycogen storage. The location of the enzymatic blockage along the metabolic path determines if the glycogen configuration is normal or abnormal ${ }^{2,3}$.

In general, a numbering system from 0 to XII has been accepted for these disorders; additionally, these can also be classified according to the affected organ and the clinical manifestations in hepatic and muscular glycogenosis ${ }^{1-4}$. The object of this presentation is to report the cases of two siblings with different clinical and biochemical manifestations of glycogenosis, which because of its characteristics corresponds to the type I or Von Gierke's disease. Photographs were taken after securing a signed informed consent, as registered in the clinical histories of both child patients, to document that exposed by the physical exam.

\section{FIRST CASE}

The case of an 11-year-old male patient, attending school from the city of Cartagena, Colombia. The history of his illness began at 11 months of age when the mother consulted because the child presented a crisis with generalized cyanosis without other aggregate symptomatology, discarding cardiac pathology. As important antecedents, the child is the product of a second pregnancy, with good apgar at birth. He was breast fed until two years of age. He revealed normal language and psychomotor development. As important personal antecedents, according to the mother an older brother also presented the same symptoms. Three months after the initial consultation, the patient presented generalized tonic-clonic crisis with a normal physical examination. At two years of age, the mother again consults because the child presented abdominal distension, weight loss, asthenia, adynamia, and generalized paleness; followed by diarrhea and abdominal pain. The physical exam at the time found generalized paleness, globe-like abdomen due to $4-\mathrm{cm}$ hepatomegaly and ascytis. The following tests were done: hemogram, platelets, TP, TPT, proteinogram, and glycemia, normal. Serology for hepatitis B was negative. Metabolic screening was initially normal; although, a second exam revealed positive Benedict, Seliwanoff, and nitrosonaphthol tests. Based on this, it was felt that the child could have congenital galactosemia and a diet was indicated for this entity. At 4 years of age, the child again presented a generalized tonic-clonic crisis associated with vomiting and the clinical exam revealed a $5-\mathrm{cm}$ homogenous hepatomegaly. Hypoglycemia with a level of $31 \mathrm{mg} / \mathrm{dl}$ was detected. A cerebral CT scan was ordered and it was reported normal. A carpogram was carried out at that moment corresponding to an osseous age of 4 years and 9 months. Further tests: TSH, T4 L were within normal limits. AST, alkaline phosphatase and LDH elevated at $829 \mathrm{U} / 1$ (Normal value: $160-320 \mathrm{U} /$ 1). The physical exam found the patient's weight at $15 \mathrm{~kg}$ (p10), height $88 \mathrm{~cm}(<\mathrm{p} 3,<5 \mathrm{SD})$ and hepatomegaly at $3 \mathrm{~cm}$. The Doppler ultrasound study confirmed the hepatomegaly and reported hepatic steatosis with normal portal flow. With these findings, type I glycogenosis is suspected and this led to recommending a fractioned diet (small, frequent feedings) supplemented with cornstarch before bedtime.

At 5 years of age, the patient presented persistent hematuria that remained with periods of asymptomatic intermittent hypoglycemia. At this age, nephromegaly was detected and a hepatic biopsy was practiced, which reported hepatic tissue with marked hepatocyte distension; with special tinctures it was possible to identify much of the positive PAS glycogen of normal structure, which is completely digested with the Diastase PAS. There was no change in fatty tissue. Electronic microscopy found displacement of organelles toward the periphery and a focal presence of glycogen granules in cytoplasm; these changes are compatible with type I glycogenosis. At 9 years of age, persistenthepatomegaly 


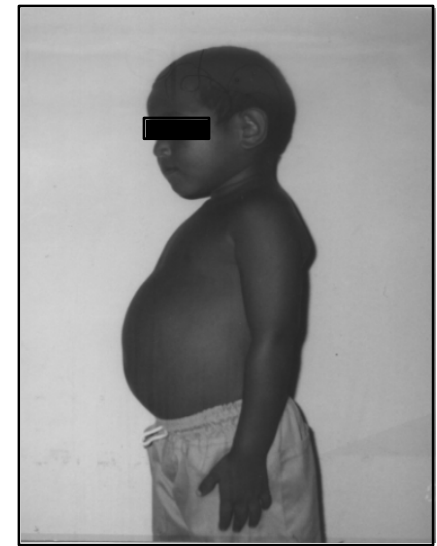

Figure 1. Child from the first case at 5 years of age, prominent abdomen is observed due to hepatomegaly previously described

and nephromegaly were found; additionally, he fractured his left arm and it did not consolidate well.

The patient is currently 11 years old, $120 \mathrm{~cm}$ tall $(<\mathrm{p} 3)$, cephalic perimeter of $50 \mathrm{~cm}<2 \mathrm{SD}$, Body Mass Index of $18.75 \mathrm{~kg} / \mathrm{m}^{2} \mathrm{SC}$, and hepatomegaly at $2 \mathrm{~cm}$ smooth with no pain reported. He is receiving an unrestricted diet and is in the $6^{\mathrm{h}}$ grade of formal education schooling with good academic performance.

\section{SECOND CASE}

14-year-old male patient, studying in the 9th grade from the city of Cartagena, Colombia. He was remitted at 8 years of age to the Biochemistry unit due to family history of glycogen storage disease (first case).

His illness began at 18 months of age with abdominal distension, aqueous diarrhea with a month and a half evolution, generalized weakness, and progressive edema on face and feet, and paleness of the skin and mucous membranes. Important antecedents: product of the first pregnancy of non-consanguineous parents, mother G2 P2 A0 C1, normal vaginal birth, pregnancy free of complications, and normal apgar at birth. His psychomotor development was normal; was breast fed by his mother until he was two years old. There is no history of epileptic crises. The physical exam found: diffuse hepatomegaly without pain $2 \mathrm{~cm}$ below the right costal and anasarca (extreme generalized edema) flange. A neurological exam proved normal. At this age, the patient was subjected to hepatic tests, as well as lab

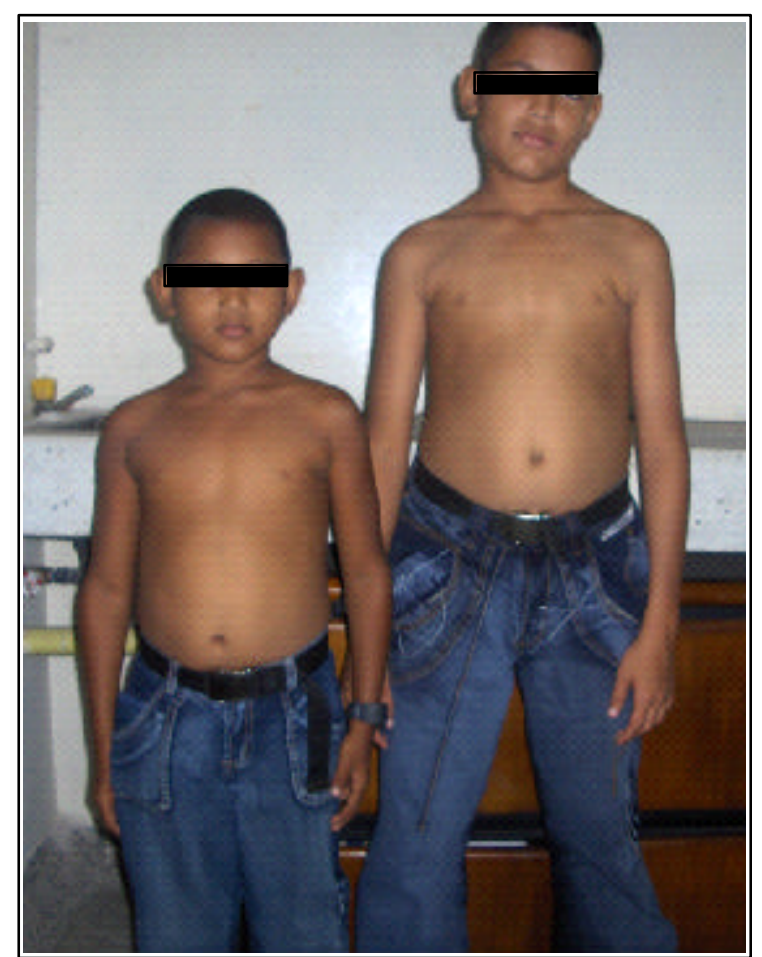

Figura 2. Case 1 at 11 years of age has diminished hepatomegaly; abdomen is less prominent than in Figure 1. Case 2 at 14 years of age; no prominent abdomen is observed, currently asymptomatic

exams for cholesterol, triglycerides, and uric acid; all were found within the upper normal limit. No data on hypoglycemia are presented, the Beneditt and Seliwanoff tests were positive, while tests for mucopolysaccharidosis resulted negative. Gammography and hepatic ultrasound tests revealed diffuse hepatomegaly. Renal ultrasound did not show alterations. Symptoms remitted at 5 years of age.

The physical exam carried out upon consultation when he was 8 years old was normal, and currently there have been no modifications of such.

\section{DISCUSSION}

Herein, we present two cases of glycogenosis in siblings with different biochemical and clinical expressions, is spite of their consanguinity. The renal and hepatic compromise and the demonstration of hypoglycemia in the younger brother (first case), which led him to 
presenting an epileptic crisis of generalized tonic-clonic type makes us consider that the type of glycogenosis is Von Gierke type I added to the fact that in the hepatic biopsy the glycogen storage was detected but with normal structure. The second case did not document symptomatic hypoglycemia or alterations in lactic acid.

The other glycogen storage diseases that present a normal glycogen structure are ${ }^{1-4}$ :

- Pompe's disease: occurs with cardiomegaly, can debut during lactation and there is no renal compromise.

- Mc Ardle, Cori type V diseases: occur with muscular cramps, muscular atrophy, and no presence of hypoglycemia.

- Hers, Cori type VI diseases: due to deficiency of hepatophosphorylase: occurs also with hepatomegaly and hypoglycemia.

Statistically, glycogenosis has a global prevalence of 1:20.000 to 1: 25.000 live births, with types I a, I b, II, III, and VI being the most common with $90 \%$ of the cases $^{2-4}$.

Glycogenosis type I or Von Gierke's disease, was discovered by German physician Gierke, who studied an 8 -year-old girl with chronic increase in liver size. After the girl's death in 1929, due to a common cold, it was proven that her liver contained $40 \%$ glycogen. The glycogen appeared normal, but it could not be degraded by the girl's liver extracts, but it could be degraded by extracts from other livers ${ }^{2,3}$.

It is the most common hereditary diseases of type I glycogen storage and, clinically, the most serious, where the cause of the disturbance is the absence of or diminishing of glucose-6-phosphatase of the liver, the intestinal mucosa, and the kidneys ${ }^{2,3}$; leading to an accumulation of abnormally high amounts of glycogen in tissues like the liver and renal tubular cells, hence, through this mechanism producing hepatomegaly and nephromegaly ${ }^{3,4}$, the first is well-described in both patients previously discussed and nephromegaly was noted in the younger patient.

Type I glycogenosis is inherited with recessive autosomal character. The gene for glucose-6-phosphatase is located in chromosome $17 \mathrm{q} 21$. The most frequent mutations responsible for this illness are known and it is possible to detect carriers and conduct prenatal diagnosis through DNA diagnostic tests. The genetic anomaly in the hydrolysis of glucose-6-phosphatase only appears once per every 200,000 individuals ${ }^{4,5}$.

Patients with type I glycogenosis may be classified into various subtypes, with the most common belonging to those who lack the glucose 6-phosphatase enzyme

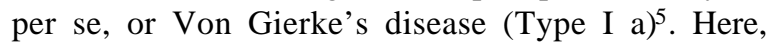
glycogen is synthesized normally and, thus, its structure is normal; but there is a failure in glycogenolysis which impedes the liberation of glucose from these deposits. In the less serious expression of this disease, the concentrations of blood glucose are normal except after stressful situations, where the normal hyperglycemic response is inhibited ${ }^{2,3}$.

The liver in these patients liberates some glucose, through the action of the debranching enzyme that helps to complete the process of glycogen hydrolysis by allowing the glycogen phosphorylase to continue degrading glycogen ${ }^{2}$.

Overproduction of purine and hyperuricemia in Von Gierke's disease are secondary effects to the greater generation of the PRPP precursor, ribose-5phosphate. A secondary lactic acidosis raises the renal threshold for urate, which leads to hyperuricemia ${ }^{2-4}$. This stems also form the increased degradation of purines in the liver; hyperlipidemia is due to the increase in the availability of lactic acid for lipogenesis and to the mobility of lipids from the adipose tissue, provoked by elevated levels of glucagon, which are a response of hypoglycemia. Hyperuricemia occurs in small children, but gout is usually not manifested prior to puberty ${ }^{2,3}$.

During physical exam, patients tend to have fat cheeks, thin extremities, short height, and protuberant abdomen due to massive hepatomegaly ${ }^{3,4}$. Although the phenotype of the patients does not correspond to what has been described, it can be noted that both are short for their ages, and with the first case revealing affectation to osseous age. The kidneys also show increase in size, as with the child in the case where nephromegaly was detected via ultrasound at 5 years of age; while the spleen and the heart are normal.

Pulmonary arterial hypertension has been described in type Ia, possibly due to an abnormally excessive production of vasoconstrictor amines like serotonin that is synthesized from the intestinal enterochromaffin cells. Hence, this becomes a plausible means in studying patients suspected of having type Ia glycogenosis; however, we should not discard the effect caused by the endothelial damage from the presence of metabolic 
alterations like hyperlipemia ${ }^{3,4}$.

The clinical manifestations are given by hypoglycemia in fasting state that can lead to epileptic crisis, which are frequent and almost invariably represent the initial disorder in children affected, as presented by the child in the first case who in two opportunities manifested generalized tonic clonic crisis without an apparently unchaining factor and with a normal physical exam. Hypoglycemia can also evolve to chronicity, as a consequence of insufficient enzyme required to obtain glucose from hepatic glycogen and from gluconeogenesis; this also occurred with the first child. Although type I glycogenosis mainly affects the liver, multiple organic systems tend to be involved. Puberty tends to be delayed in this disease. Frequent fractures and radiological signs of osteopenia are not rare in adults and the mineral content of radium is significantly reduced in pre-puberty patients; this would be the cause of the fracture noted in the first patient. Hematomas and epistaxis are frequent and are associated to prolonged coagulation times consequential of the alteration of platelet aggregation and adherence ${ }^{2-4}$.

Among the laboratory findings, besides hypoglycemia, we can find: lactic acidosis, ketosis and hyperlipidemia, this last one predisposes a greater risk for pancreatitis, atherosclerosis, and cerebrovascular events ${ }^{3,4}$. Lactic academia appears because the liver cannot effectively use lactate to synthesize glucose. Additionally, in response to glucagon the liver produces even more lactic acid. This hormone should unleash the liberation of glucose without lactate production; nevertheless, the contrary occurs given the lack of glucose-6-phosphatase. Anemia may be present and it is of multifactorial etiology, contributing factors like recurrent chronic infection, intestinal inflammatory disease, iron, vitamin B12, or folic acid nutritional deficiencies. Furthermore, stunted growth can be provoked by excessive counter-regulating hormones like cortisol, which is secreted during chronic hypoglycemia ${ }^{3-5}$.

Patients with type I glycogenosis may debut during the neonatal period with hypoglycemia and lactic acidosis and even hepatomegaly; however, this disease generally tends to appear at 3-4 months of age with hepatomegaly or hypoglycemic crisis ${ }^{5}$. Although it is true that the age of onset of the symptoms can be as early as the neonatal stage, the two cases reported went without symptoms until the late lactating stage, thus, the clinical alterations appeared at that age. It must be indicated that these children were breast fed up to two years, which could have favored the delay in the onset of the symptoms because they received fractioned feedings.

The gravity of the disease reaches a plateau after the fourth or fifth year of life, as with the older sibling who did not show symptoms until he was five years old. But other patients present by this age hepatic adenomas that may bleed and that in some cases turn into malignant neoplasias. For this, currently makers are used like globular sedimentation velocity (GSV) and alkaline phosphatase that frequently increase in the presence of adenomas, as well as serum? -fetoprotein that is elevated exclusively in cases of hepatocellular carcinoma ${ }^{1}$. Other complications are pulmonary hypertension and nephrocalcinosis, nephrolithiasis and nephropathy that lead to renal failure, requiring dialysis and renal transplant ${ }^{3,4}$. If we note in the first case, in spite of transpiring with hepatic compromise for 9 years, tumors have not been documented at that level nor have there been complications of renal origin. When the children with this disease mature, they become normoglycemic and characteristically present abnormal glucose tolerance curves. This is why the carbohydrates must be watched in the diet, given that excessive glucose leads to glycogen storage in the liver and kidneys ${ }^{3,4}$. This characteristic may be observed in the first case after starting treatment with cornstarch as of 4 years of age and with the passage of time, the diet is now normal and the 11 year-old boy currently has not presented any hypoglycemia crisis.

The diagnosis of type I glycogenosis is suspected because of the clinical presentation and the presence of abnormal concentrations of lactate and lipids. Administering glucagon or adrenalin determines a small or nil increase of the glycemia, while the concentration of lactate increases considerably. The definite diagnosis requires a hepatic biopsy to demonstrate the deficit of enzymatic activity, although the enzymatic activity can also be measured in the peripheral leucocytes and in a biopsy if the small intestine. Identifying mutations of genes of glucose-6-phosphatase offers a non-invasive diagnostic method for most patients with type I glycogenosis ${ }^{3}$. In the cases described, it was not possible to conduct a measurement of the enzymatic activity, although with the patient of the first case an anatomopathological and histological study was conducted with 
the corresponding tinctures, which allowed proving glycogen storage with normal structure. If we correlate clinical aspects with the cardinal symptoms of hypoglycemia associated to hepatomegaly and nephromegaly, we should consider a glycogen storage disease: Von Gierke's disease.

The treatment is designed to keep glycemia normal, which is accomplished through continuous infusion of glycosides in the intestine through a nasogastric intubation or oral administering of raw cornstarch; thus, alleviating the symptoms and avoiding hypoglycemia. The treatment with cornstarch is based on the fact that the starch is hydrolyzed by the intestinal glucoamylase and the pancreatic amylase and it is useful in older children, adolescents, and adults with a dosage of 1.5 to $2 \mathrm{~g} / \mathrm{kg}$ / day, which aids in keeping the level of glycemia normal for a period of 4 to 10 hours, as long as the initial glycemia was normal. For a better effect in this therapy, the cornstarch should be raw, mixed with cold water to keep the granules from hydrolyzing and making the treatment less effective. In some patients, some secondary effects may be noted like occasional diarrhea, abdominal distension, and flatulence, but these are usually transitory $^{3-5}$.

Because fructose and galactose cannot directly become glucose, their ingestion should be restricted and it is recommended to administer calcium and multivitamin supplements ${ }^{3-5}$.

Dietary treatment improves hyperuricemia, hyperlipidemia, and renal function, preventing renal insufficiency. However, after puberty the use of allopurinol and hypolipemiants ${ }^{2}$ is required. Bearing in mind that both children are currently in their adolescent stage, the levels of uric acid and lipids have to be watched for early detection of any metabolic alteration of this type. Microalbuminuria is treated with angiotensin converting enzyme inhibitors (ACEI) like captopril. Citrate supplements are beneficial to prevent or improve nephrocalcinosis and the development of kidney stones ${ }^{2-4}$.

As an alternate treatment, hepatic or hepatocytes transplant and transposition of the portal vein have been undertaken, creating a portacaval shunt that increases peripheral blood glucose by keeping portal blood from going into the liver. However, given complications inherent to this treatment in the short and long term, it is recommended only for patients with hepatic cancer ${ }^{3,4}$.
As for the prognosis, it is known that long-term complications tend to appear in adults whose illnesses have not been treated adequately during childhood; currently, early diagnosis and efficient treatment have notably improved the result. Nevertheless, nephropathy and the formation of hepatic adenomas continue being serious complications ${ }^{1,5}$.

\section{RECOMMENDATIONS}

- Within the innate errors of metabolism, glycogen storage diseases are infrequent and, as with all of them, these should be considered in patients with unusual symptomatology.

- It is also important to know hoe to interpret the metabolic screening tests to avoid diagnostic errors as occurred with one of the patients presented, who was diagnosed with galactosemia afterfinding positive for the Seliwanoff test, which is compatible with fructose-related disorder.

- The treatment may be focused three ways: fractioned diet based on raw cornstarch, hypolipemiant medications and allopurinol, surgical intervention with hepatic or hepatocyte transplant.

- It is necessary to continue investigating and establish networks with other institutions and/or research groups to improve diagnoses with cutting-edge technology that will permit us to determine the enzymatic activity and the different mutations of these metabolic diseases of genetic origin.

\section{REFERENCES}

1. David A, Weinstein D, Wolfsdorf J. Glycogen storage disease: A primer for clinicians. Endocrinologist 2002; 12:531-8.

2. Alvear C. Bioquímica humana: de las bases a la clínica. Cartagena: Editorial Universitaria de Cartagena; 2007.p. 598600.

3. Scriver CR. Lisosomal disorders. In: Scriver CR. The metabolic and molecular bases of inherited disease. $8^{\text {th }}$ ed. London: Mc Graw Hill; 2001.

4. Menkes JH. Metabolic disease of the nervous system. In: Menkes JH, Sarnat HB, Maria BL (eds). Child neurology. $7^{\text {th }}$ ed. Philadelphia: Lippincott Williams \& Wilkins; 2007. p. 6772.

5. Moraru E, Cuvinciuc O, Antonesei L, Mihaila D, Bozomitu L, Rusul T, et al. Glycogen storage disease type I-between chronic ambulatory follow-up and pediatric emergency. $J$ Gastrointestin Liver Dis. 2007; 16:47-51. 